\title{
Association of Occupational Stress and Social Support with Health- related Behaviors among Chinese Offshore Oil Workers
}

\author{
Wei-Qing $\mathrm{CHEN}^{1}$, Tze Wai Wong ${ }^{2}$ and Ignatius Tak-Sun Yu ${ }^{2}$ \\ ${ }^{1}$ Department of Biostatistics and Epidemiology, School of Public Health, Sun Yat-sen University and ${ }^{2}$ Department \\ of Community \& Family Medicine, The Chinese University of Hong Kong, Hong Kong SAR, China
}

\begin{abstract}
Association of Occupational Stress and Social Support with Health-related Behaviors among Chinese Offshore Oil Workers: Wei-Qing $C_{H E N}$, et al. Department of Biostatistics and Epidemiology, School of Public Health, Sun Yat-sen University, China-To explore the relationship of occupational stress and social support with healthrelated behaviors of smoking, alcohol usage and physical inactivity, a cross-sectional survey was conducted among 561 offshore oil installation workers of a Chinese state-owned oil company. They were investigated with a self-administered questionnaire about socio-demographic characteristics, occupational stress, social support and health-related behaviors. Logistic regression analysis was used to study the association between occupational stress, social support and health-related behaviors and adjusted for age, educational level, marital status, duration of offshore work and job title. Of 561 workers, 218 (38.9\%) were current smokers, 124 (22.1\%) current drinkers, and 354 $(63.1 \%)$ physically inactive in their leisure time. Further multivariate logistic regression analysis indicated that: (1) Current smoking was significantly negatively related with perceived stress from "Safety" $(\mathrm{OR}=0.74 ; 95 \%$ $\mathrm{Cl}=0.58 \sim 0.94)$ and lack of supervisors' instrumental support (OR=0.34; 95\% Cl=0.18 0.65); (2) Current drinking was significantly positively related to perceived stress from "Interface between job and family/social life" (OR=1.32; 95\% $\mathrm{Cl}=1.02 \sim 1.70)$ and "Organizational structure" (OR=1.35; 95\% Cl=1.06 1.74), but was significantly negatively related to poor emotional support from friends (OR=0.54; 95\% Cl=0.62 0.96); (3) Physical inactivity after work was significantly positively associated with perceived stress from "Safety" (OR=1.44; 95\% Cl=1.16 1.79) and lack of
\end{abstract}

Received Nov 7, 2007; Accepted Feb 22, 2008

Published online in J-STAGE Apr 11, 2008

Correspondence to: $W .-Q$. Chen, Department of Biostatistics and Epidemiology, School of Public Health, Sun Yat-sen University, 74, Zhongshan Road 2, Guangzhou, PR China

(e-mail: chenwq@mail.sysu.edu.cn) instrumental support from both supervisors $(\mathrm{OR}=1.74$; $95 \% \mathrm{Cl}=1.16 \sim 2.65)$ and friends $(\mathrm{OR}=1.68 ; 95 \%$ $\mathrm{Cl}=1.06 \sim 2.42)$. The findings suggest that psychosocial factors of occupational stress and social support at offshore oil work might affect workers' health-related behaviors in different ways.

(J Occup Health 2008; 50: 262-269)

Key words: Occupational stress, Social support, Health-related behaviors, Association, Offshore work, Chinese

According to modern occupational stress theories, occupational stress may affect workers' health through two separate mechanisms ${ }^{1-3)}$. First, acting directly via the organism's main stress axes, occupational stress can affect the psychophysiological responses (autonomic, neuroendocrine, and immune) that are implicated in pathology and host vulnerability, reducing resistance to pathogens or directly stimulating disease mechanisms. Second, an indirect pathway operating via behavioral decisions or habits of people exposed to work stress, and this means that occupational stress may lead to the adoption of unhealthy behaviors such as smoking, alcohol consumption, physical inactivity and unhealthy eating habit.

Many studies have indicated that perceived stress at work is associated with unhealthy behaviors of workers, but their results are inconsistent. Some studies found that occupational stress was positively associated with smoking behavior and the amount of cigarettes smoked ${ }^{3-7}$. Such associations have not been found in other studies ${ }^{8,9)}$. Five studies consistently showed that occupational stress was related to workers' alcohol usage ${ }^{8-12)}$. A similar association was also observed between perceived stress from different sources at work and workers' physical exercise outside work $^{4-6)}$. By contrast, Linquist et al. found that occupational stress and work/home stress had no influence on workers' exercise habits in leisure time ${ }^{10)}$.

Social support is the perception that an individual is a 
member of a complex network in which one can give and receive affection, aid and obligation ${ }^{13)}$. Previous studies consistently showed that social support was related to health-related behaviors. Allen et al. ${ }^{14)}$ reported that social support was positively associated with more physical exercise and less smoking and alcohol consumption, and that these associations were modified by a hostile personality. Milligan et al. ${ }^{15)}$ showed that lack of family social support was a barrier to smoking cessation and drinking moderation. A study by Gu et al. in China ${ }^{16)}$ indicated that the amounts of cigarette and alcohol consumed were significantly increased with a reduction of social support from one's colleagues.

Work on offshore oil installations is generally regarded as a stressful occupation. Apart from receiving stressors that are common to most workplaces onshore, the workers are also exposed to stressors that are specific to the offshore setting ${ }^{17-19)}$. The physical stressors included noise, vibration, poor lighting and ventilation, confined living and working space, adverse offshore weather conditions, long working hours and shift work. Psychosocial stressors cover job characteristics (work load, variety, clarity, control), perceived risk (fire, explosion, blow out, traveling by helicopter or ships, etc), job insecurity, and work-family interface. Due to the isolation of working on offshore oil installation, some of social supports are not available to offshore workers. Therefore, it is important to find the influence of occupational stress and social support on the workers' health-related behaviors in such a special work environment. To our knowledge, there has not been any report in this field, in particular, among Chinese offshore oil workers. The aims of this paper were to explore the prevalence of smoking, alcohol usage and physical exercise after work among a group of Chinese offshore oil workers, and to determine the relationship of these behaviors with occupational stress and social support.

\section{Methods}

\section{Study subjects}

The study subjects were offshore workers from an offshore oil company in Southern China, which employed about 1,100 male offshore oil workers working on five installations. The offshore workers were divided into two groups that took rotations to work for $4 \mathrm{wk}$ on the platforms at sea, followed by $4 \mathrm{wk}$ of rest onshore. So at any time, about half of the offshore workers would be working offshore and the other half resting onshore. To achieve smooth production on the platforms, the proportion of senior and junior workers in each shift group is fixed ${ }^{20,21)}$. In addition, the job positions on each platform are also fixed. Therefore, the two groups were more or less equal in terms of their ranks, work experience, age structure and distribution of job categories. We surveyed all the workers $(\mathrm{N}=581)$ during their onshore rotation and $561(96.6 \%)$ completed the questionnaire.

Before administering the questionnaire, several trained investigators explained to all the subjects the aims of study, the contents of the questionnaire, and how to complete it. Written informed consent was then obtained. As the workers filled in the questionnaires, the investigators were present to answer any queries. They also checked all questionnaires for missing data and followed up to obtain the relevant information. The study was approved by the Ethical Committee of the Sun Yatsen University.

\section{Measurement of independent variable}

Occupational stress was measured by the Occupational Stress Scale (OSS), developed from the questionnaire used in previous studies of offshore workers in the U.K. ${ }^{22-}$ 24). The Occupational Stress Scale (OSS) with 51 items covered the following domains: factors intrinsic to the job, career and achievement, relationship with others at the work, safety, managerial role, and interface between job and social, and family life. Subjects were asked: "Are the following items a source of stress to you?" A six-point Likert-type scale was used for their response to each item, ranging from 1 (indicating no stress) to 6 (indicating high stress). (1=Very definitely is not a source, $2=$ Definitely is not a source, $3=$ Generally is not a source, $4=$ Generally is a source, $5=$ Definitely is a source, $6=$ Very definitely is a source). The validity and reliability of our instrument have been assessed in another paper ${ }^{25}$.

Two types of social support (instrumental support and emotional support) from four sources (supervisors, colleagues, wife/families, and friends) were assessed by rating with a 4 -point Likert scale ( $1=$ never, $2=$ a few, $3=$ some times, and $4=$ often). In the multivariate analysis, the social support of each type and its source was dichotomized into "strong support" (often) and "lack of support" (never, a few, or sometimes).

\section{Measurement of dependent variable}

Health-related behaviors including smoking, drinking alcohol, and physical exercise were assessed by a selfreporting method. Smoking habit was measured by the question: "Do you smoke?" There were three choices for the question: $0=$ never, $1=$ ex-smoker (having given up smoking for one year or more), and $2=$ current smoker (regularly smoking of at least one cigarette per day and continuing this habit for at least one year).

Drinking habit was measured by the question: "Do you drink?" There were three choices for the question: $0=$ never, $1=$ ex-drinker (having given up drinking for one year or over), and $3=$ current drinker (regularly drinking alcohol at least one time per week and continuing this habit for at least one year).

The subjects were asked by the question: "How often 
Table 1. Demographic traits and health-related behaviors of 561 offshore oil workers

\begin{tabular}{|c|c|c|c|c|c|}
\hline Demographic traits & Number & Proportion (\%) & Health-related behaviors & Number & Proportion $(\%)$ \\
\hline Education level: & & & Do you smoke? & & \\
\hline Primary school & 28 & 5.0 & Never smokers & 304 & 54.1 \\
\hline Secondary school & 100 & 17.8 & Ex-smokers & 39 & 7.0 \\
\hline High/technical secondary school & $1 \quad 278$ & 49.6 & Current smokers & 218 & 38.9 \\
\hline Junior college & 87 & 15.5 & Do you drink? & & \\
\hline University & 68 & 12.1 & Never drinkers & 429 & 76.5 \\
\hline Marital status: & & & Ex-drinkers & 8 & 1.4 \\
\hline Unmarried & 177 & 31.6 & Current drinkers & 124 & 22.1 \\
\hline Married & 384 & 68.4 & $\begin{array}{l}\text { How often do you take physical } \\
\text { exercise after work? }\end{array}$ & & \\
\hline Job title: & & & Never & 24 & 4.3 \\
\hline Drilling workers & 103 & 18.4 & Occasionally & 330 & 58.8 \\
\hline Attending personnel & 60 & 10.7 & Regularly & 207 & 36.9 \\
\hline Deck workers & 55 & 9.8 & & & \\
\hline Electricians & 41 & 7.3 & & & \\
\hline Mechanics & 32 & 5.7 & & & \\
\hline Service workers & 29 & 5.2 & & & \\
\hline Manager & 41 & 7.3 & & & \\
\hline Material workers & 22 & 3.9 & & & \\
\hline Power workers & 21 & 3.7 & & & \\
\hline Derrick workers & 22 & 3.9 & & & \\
\hline Turbine workers & 17 & 3.0 & & & \\
\hline Other & 118 & 21.0 & & & \\
\hline
\end{tabular}

do you take physical exercise after work?" There were three choices for the question: $0=$ never, $1=$ occasionally, and $2=$ usually. The subjects who selected "never" or "occasionally" were categorized as "lack of physical exercise".

\section{Other variables}

The following socio-demographic factors: age, total years of working on the platform, educational level, marital status and job title were sought.

\section{Data analyses}

First, the frequencies of smoking, alcohol consumption, and physical activity after work were determined. Second, to determinate the relationship of the other factors with smoking, alcohol consumption and physical inactivity, a series of univariate and multivariate logistic regressions were separately conducted. In logistic regression, smoking, alcohol consumption and physical activity after work were regarded as dependent variables and respectively dichotomized into 'current smokers,' 'current drinkers,' and 'physical inactivity' (coded 1), and 'never or ex-smoker,' 'never or ex-drinker,' and 'physical activity' (coded 0). Occupational stress and social supports were treated as independent variables. Considering the findings that some socio-demographic characteristics were significantly associated with both perceived occupational stress ${ }^{26}$ ) and health-related behaviors $^{27-29)}$, age, educational level, marital status, duration of offshore work and job title were adjusted in multivariate logistic regression. Odds ratio (OR) with $95 \%$ confidence interval $(95 \% \mathrm{CI})$ was used to indicate the strength of the association.

A summary of the study variables and their definition or values is presented in the Appendix table.

\section{Results}

Socio-demographic characteristics of subjects

Of the population of 581 workers, 561 (96.6\%) workers completed all the questions in the questionnaire. Their mean age was $32.43(\mathrm{SD}=8.65)$ years old with the range of 20 to 60 , and the average duration of working on platforms was $8.24(\mathrm{SD}=7.39)$ years with a range of 1 to $40 \mathrm{yr}$. Other socio-demographic traits are shown in Table 1.

Descriptive analysis of smoking, alcohol consumption, physical exercise

Among the 561 workers, 39 (7.0\%) were ex-smokers, and $218(38.9 \%)$ current smokers; $124(22.1 \%)$ were current drinkers, and 8 (1.4\%) ex-drinkers; And 207 $(36.9 \%), 330(58.8 \%)$, and $24(4.3 \%)$ workers 
Table 2. Univariate logistic regression analysis for psychosocial risk factors with health-related behaviors presented by odds ratio (OR) and $95 \%$ confidence intervals (95\% CIs)

\begin{tabular}{llll}
\hline Psychosocial factors & Current smoking & Current drinking & Physical inactivity \\
\hline Occupational stressors & & & \\
$\quad$ Interface between job and family/social life & $0.86(0.72 \sim 1.02)$ & $1.05(0.86 \sim 1.28)$ & $1.13(0.95 \sim 1.34)$ \\
Career and achievement & $0.96(0.80 \sim 1.14)$ & $0.96(0.79 \sim 1.17)$ & $0.92(0.78 \sim 1.09)$ \\
Safety & $0.86(0.73 \sim 1.03)$ & $1.12(0.92 \sim 1.36)$ & $1.25(1.05 \sim 1.49)^{*}$ \\
Management problem and relationship with others at work & $1.11(0.93 \sim 1.33)$ & $1.17(0.97 \sim 1.42)$ & $1.10(0.92 \sim 1.31)$ \\
Physical environment of work place & $1.18(0.99 \sim 1.40)$ & $1.10(0.90 \sim 1.35)$ & $1.10(0.93 \sim 1.31)$ \\
Living in environment & $1.08(0.90 \sim 1.28)$ & $0.95(0.78 \sim 1.16)$ & $0.93(0.78 \sim 1.10)$ \\
Managerial role & $1.00(0.84 \sim 1.19)$ & $1.04(0.85 \sim 1.27)$ & $1.06(0.89 \sim 1.25)$ \\
Ergonomics & $1.37(1.14 \sim 1.64) * * *$ & $1.13(0.93 \sim 1.38)$ & $0.93(0.78 \sim 1.10)$ \\
Organizational structure & $0.87(0.73 \sim 1.04)$ & $1.10(0.90 \sim 1.34)$ & $0.92(0.78 \sim 1.09)$ \\
Social support & & & \\
Instrumental support from supervisors & $0.69(0.45 \sim 1.03)$ & $0.96(0.60 \sim 1.53)$ & $1.59(1.35 \sim 2.42)^{* * *}$ \\
Instrumental support from colleagues & $1.52(0.93 \sim 2.50)$ & $1.92(1.14 \sim 3.24)^{*}$ & $1.16(1.03 \sim 2.48)^{*}$ \\
Instrumental support from wife/families & $0.80(0.57 \sim 1.14)$ & $0.68(0.45 \sim 1.01)$ & $0.77(0.55 \sim 1.09)$ \\
Instrumental support from friends & $1.36(0.95 \sim 1.95)$ & $1.51(1.00 \sim 2.27)^{*}$ & $1.70(1.17 \sim 2.46)^{* * *}$ \\
Emotional support from supervisors & $0.59(0.41 \sim 0.84)^{* *}$ & $0.79(0.53 \sim 1.19)$ & $1.04(0.45 \sim 2.24)$ \\
Emotional support from colleagues & $1.10(0.74 \sim 1.64)$ & $0.94(0.59 \sim 1.49)$ & $1.62(1.07 \sim 2.44)^{*}$ \\
Emotional support from wife/families & $0.84(0.59 \sim 1.21)$ & $0.77(0.50 \sim 1.17)$ & $1.04(0.73 \sim 1.48)$ \\
Emotional support from friends & $1.24(0.83 \sim 1.85)$ & $1.50(0.99 \sim 2.29)$ & $1.23(1.09 \sim 2.33)^{*}$ \\
\hline
\end{tabular}

$* p<0.05, * * p<0.01, * * * p<0.001$

respectively had regular, some, and no physical exercise. According to our definition, 354 (63.1\%) subjects were categorized as "lack of physical exercise after work." For more details see Table 1 .

Association of smoking, alcohol consumption and physical inactivity with occupational stress and social support

Table 2 presents the results of univariate logistic regression analysis for the psychosocial factors with the three behaviors. Current smoking was significantly positively associated with perceived stress from "ergonomics" and negatively associated with a lack of supervisors' emotional support. Current drinking was significantly positively related to lack of instrumental support from both colleagues and friends. Physical inactivity after work was significantly positively associated with perceived stress from "interface between job and family/social life" and "organizational structure," lack of instrumental support from supervisors, colleagues and friends and lack of emotional support from both colleagues and friends.

Table 3 presents the results of multivariate logistic regression analysis for occupational stress and social support with the three behaviors with adjustments for age, education level, marital status, years of offshore work and job title. Current smoking was significantly negatively with perceived stress from "safety," lack of supervisors' instrumental support. Perceived stress from "interface between job and family/social life" and "organizational structure" were significantly positively related to current drinking, whilst poor emotional support from friends was significantly and negatively associated with it. Perceived stress from "safety" and lack of instrumental support from both supervisors and friends were significantly positively associated with physical inactivity after work.

\section{Discussion}

Strengths and limitations of the study

This was the first study on association of occupational stress and social support at work with health-related behaviors among Chinese offshore oil installation workers. The study subjects (about $50 \%$ of all offshore oil installation personnel) were "captured" on their onshore at rest and were not sampled by a random process. Yet, there were no obvious biases in this sample of about $50 \%$ of the entire workforce. Due to the demands of smooth oil production, administrative concerns, and the fixed structure of job positions on the platforms, the working experience, age proportion and job titles of those workers working on platforms (one half) and those resting on land (the study subjects) were comparable ${ }^{20,21)}$. Therefore, the results could be generalized to the other half of workers in the "working cycle." The occupational stress scale (OSS) as a widely used psychosocial scale 
Table 3. Multivariate logistic regression analysis for psychosocial risk factors with health-related behaviors after adjusting for age, educational level, marital status, duration of offshore employment and job title presented by odds ratio (OR) and 95\% confidence intervals (95\% CIs)

\begin{tabular}{llll}
\hline Psychosocial factors & Current smoking & Current drinking & Physical inactivity \\
\hline Occupational stressors & & & \\
Interface between job and family/social life & $0.87(0.68 \sim 1.11)$ & $1.32(1.02 \sim 1.70)^{*}$ & $1.19(0.90 \sim 1.39)$ \\
Career and achievement & $1.01(0.80 \sim 1.29)$ & $1.06(0.83 \sim 1.36)$ & $0.95(0.77 \sim 1.18)$ \\
Safety & $0.74(0.58 \sim 0.94)^{*}$ & $1.06(0.83 \sim 1.34)$ & $1.44(1.16 \sim 1.79)^{*}$ \\
Management problem and relationship with others at work & $1.17(0.93 \sim 1.48)$ & $1.13(0.90 \sim 1.42)$ & $1.03(0.84 \sim 1.27)$ \\
Physical environment of work place & $1.02(0.80 \sim 1.29)$ & $1.04(0.81 \sim 1.32)$ & $1.07(0.86 \sim 1.32)$ \\
Living in environment & $0.99(0.78 \sim 1.27)$ & $0.82(0.65 \sim 1.04)$ & $0.83(0.68 \sim 1.02)$ \\
Managerial role & $0.89(0.71 \sim 1.12)$ & $0.97(0.77 \sim 1.29)$ & $0.98(0.80 \sim 1.20)$ \\
Ergonomics & $1.18(0.93 \sim 1.51)$ & $1.00(0.78 \sim 1.29)$ & $0.85(0.68 \sim 1.05)$ \\
Organizational structure & $1.14(0.90 \sim 1.45)$ & $1.35(1.06 \sim 1.74)^{*}$ & $0.93(0.76 \sim 1.15)$ \\
Social support & & & \\
Instrumental support from supervisors & $0.34(0.18 \sim 0.65)^{* * *}$ & $0.61(0.33 \sim 1.15)$ & $1.74(1.113 \sim 2.65)^{*}$ \\
Instrumental support from colleagues & $1.62(0.77 \sim 3.42)$ & $1.85(0.91 \sim 3.79)$ & $1.61(0.75 \sim 3.45)$ \\
Instrumental support from wife/families & $0.98(0.51 \sim 1.90)$ & $0.59(0.30 \sim 1.18)$ & $0.53(0.29 \sim 0.97)$ \\
Instrumental support from friends & $1.18(0.64 \sim 2.16)$ & $1.49(0.78 \sim 2.83)$ & $1.68(1.06 \sim 2.42)^{*}$ \\
Emotional support from supervisors & $0.78(0.46 \sim 1.33)$ & $1.46(0.82 \sim 2.59)$ & $1.28(0.79 \sim 2.32)$ \\
Emotional support from colleagues & $1.33(0.74 \sim 2.41)$ & $0.84(0.44 \sim 1.62)$ & $0.97(0.56 \sim 1.68)$ \\
Emotional support from wife/families & $1.00(0.53 \sim 1.91)$ & $0.82(0.43 \sim 1.59)$ & $1.78(0.98 \sim 3.23)$ \\
Emotional support from Friends & $1.11(0.62 \sim 1.99)$ & $0.54(0.32 \sim 0.96)^{*}$ & $1.30(0.75 \sim 2.25)$ \\
\hline
\end{tabular}

$* p<0.05, * * p<0.01, * * * p<0.001$

\#: The adjustment factors were entered into the model by force in block 1 and the psychosocial factors were then entered into the model by force in block 2 .

has been proven to be a valid and reliable tool for measuring occupational stress ${ }^{25)}$. It was based on the occupational stress theory proposed by Cooper et al. in their research on offshore oil workers in the North Sea oilfield in the U.K. The scale has been shown to have a high specificity, and potential confounding factors were controlled in the analyses of the associations of occupational stress and social support with the healthrelated behaviors.

There are several limitations in this study. First, owing to the cross-sectional nature of the study design, causal relationships could not be determined. Second, in the data collection process, a self-administered questionnaire was used, in which information bias is always a possibility. One possible bias might be the exaggeration of perceived work stress, with an underlying motive to prompt management to improve workers' work conditions or their pay packages to compensate for the bad working conditions. Another possible bias might be the underreporting of smoking and drinking. Smoking is not permitted in working areas, while drinking alcohol is prohibited during the offshore work cycle. Moreover, the survey was conducted in the period of the workers' onshore rest, in which they might report less work stress than when they had worked offshore, because onshore rest might have made the workers temporarily free of work environment and job stress. This potential information bias might distort the true association of smoking and drinking with the occupational stress and social support studied. The company policy of prohibition of alcohol consumption during the offshore work cycle might have resulted in under-reporting of alcohol use, even while the workers were resting onshore. Although well-trained investigators were present during the whole process of the data collection to explain to the workers how to complete the questionnaire, workers who were poorly educated might still have misunderstood the meaning of the questionnaire. In the data analysis, multivariate statistical tests were performed for a large number of variables, and some associations might have arisen by chance. Hence, associations of borderline statistical significance have to be interpreted with caution. Moreover, the amount of smoking and drinking alcohol and frequency of physical exercise were not quantified. Hence, we could not explore their dose-response relationship with the psychosocial factors.

Association of occupational stress and social support with smoking

Smoking is a complex phenomenon, which is 
influenced by psychosocial factors, such as occupational stress, social support and socio-demographics ${ }^{3)}$. Researchers have studied work stress extensively as an important cause of smoking in the past decades. However, conflicting results have been obtained. Two studies indicated that work stress had no impact on smoking ${ }^{9,10)}$, while another five studies unanimously reported that perceived work stress was positively related to smoking behavior or the intensity of smoking cigarettes ${ }^{4-8)}$. Being inconsistent with the previous studies' findings, the present study showed that only perceived stress from "safety," among the nine perceived sources of occupational stress, was significantly and negatively associated with current smoking. A possible reason is that workers perceiving higher stress from "safety" realized smoking to be a dangerous behavior on the platform (such as causing fire risk), therefore, they might have smoked less than those perceiving lower stress from "safety."

Several previous studies ${ }^{14-16)}$ witnessed that high social support was associated with less smoking. Contrary to these results, we found that the lack of instrumental support from supervisors was significantly and negatively associated with current smoking. Sometimes, smoking a cigarette is a social habit and can be used as a social tool for nurturing and improving personal relationships with others or as a gesture of friendship, and a person's smoking initiation and maintenance is affected by his peer group pressure ${ }^{30)}$. The workers lack of instrumental support from supervisors might indicate that they had poor personal relationships and connections with colleagues, and also that they were less exposed to the pressure of their colleagues' smoking behavior and thus, smoked less.

\section{Association of occupational stress and social support with drinking alcohol}

Since ancient times, people have observed a complex relationship between alcohol consumption and stress. Not only have stressful situations induced drinking, but alcohol consumption has long been considered a way of relieving stress ${ }^{31)}$. Some researchers reported that drinking behavior was influenced by factors outside the workplace, as well as the work environment itself ${ }^{32)}$. Sayette divided drinkers into social drinkers and problem drinkers $^{31)}$. The association between occupational stress and drinking is still controversial. A study by Roxburgh found that jobs with high substantive complexity significantly decreased alcohol consumption, but job demands and noxiousness significantly increased $i^{11}{ }^{11}$. A longitudinal study ${ }^{12)}$ and a cross-sectional study ${ }^{10)}$ both indicated that work stress was significantly positively associated with drinking status. But, inverse associations with current drinkers and alcohol consumption per day were found for high job demands, low decision latitude and job strain by Greenlund et al. ${ }^{9)}$

As the company prohibited alcohol consumption during the offshore work cycle, the drinking habit of the subjects just reflected the alcohol consumption in the resting cycle on land. The company policy might imply that the offshore personnel were less likely to relieve work-related stress through drinking alcohol. Therefore, habitual drinkers were required to modify their habit at work, which might impose a problem, and could be a likely reason that drinkers perceived more stress from "organizational structure" than non-drinkers did.

Studies by Allen et al. ${ }^{14)}$, Milligan et al. ${ }^{15)}$ and $\mathrm{Gu}$ et $a l .{ }^{16)}$ independently proved that high social support could decrease alcohol consumption. Contrary to their findings, our study found that lack of friends' emotional support was negatively related to current drinking. Like smoking, drinking alcohol was often used for improving social relationships with others Chinese, and this behavior may be reinforced by group norms. This might explain why those workers who perceived less emotional support from friends were negatively associated with current drinking.

Association of occupational stress and social support with physical exercise in leisure time

Some researchers think that high physical and mental job demands can lead to sedentary behavior since the demands will result in fatigue and a need for long recovery time after work ${ }^{5}$. This has led many researchers to use Karasek's model, without considering other stressors at work or other mechanisms through which work stress might affect the workers' physical exercise behavior ${ }^{6-10)}$. Recently, two studies on job stress, measured with different scales, and health-related behaviors were reported. First, the study of Johansson et al. ${ }^{5}$ ) found that sedentary behavior was positively associated with hazardous exposure in males and psychological demands in females, respectively, but was negatively associated with learning opportunities. In another study ${ }^{10)}$, it was observed that physical exercise was not associated with job stress and home/work stress measured with OSI (Occupational Stress Indicator).

In the present study, we found that lack of physical exercise in leisure time was positively associated with lack of instrumental support from supervisors and friends, and perceived stress from "safety." As we know that some physical exercises are collective activities and are performed in groups, which might explain the finding that workers with higher social support from supervisors and friends performed more physical exercises. Space on an offshore oil installation is confined and it cannot provide a special safe place for the workers to perform physical exercise after work, and they just do it in limited living areas without enough safety equipment. Therefore, the workers perceiving more stress from "safety" might consider physical exercise on platforms being as, and this 
was why perceived stress from "safety" was negatively associated with physical exercise in leisure time on the platforms.

Moreover, comparing the results for the association of perceived occupational stress from offshore oil work and social support with smoking, alcohol use and physical inactivity between univariate analysis and multivariate analysis, we found the results for physical inactivity were more consistent than those for smoking or drinking alcohol. What caused the difference? The possible reasons are as follows. First, for safe production, smoking and drinking alcohol are respectively prohibited in working areas and in the period of offshore working, but physical exercise is permitted while working on the platforms. Hence, the workers may use these behaviors to cope with work stress in different ways. Second, age, educational level, marital status, duration of offshore and job title were controlled for as potential confounders in multivariate logistic regression analysis, but these variables differently impacted the occupational stress ${ }^{26)}$, and the three health-related behaviors ${ }^{27-29)}$. Third, it was possible that social supports differently impacted the offshore workers' perceiving occupational stress from offshore oil work ${ }^{26}$. Therefore, when age, educational level, marital status, duration of offshore and job title as well as social supports were forced into the logistic regression model, the association of the perceived occupational stress and social supports with smoking and drinking alcohol might have been different with physical inactivity between univariate analysis and multivariate analysis.

In summary, the results of our study suggest that occupational stress and social support in offshore oil work might affect workers' health-related behaviors in different ways.

Acknowledgments: The authors wish to express their gratitude to their colleagues at the Worker's Hospital of the West Company of South Sea of Chinese Offshore Oil Company and all the offshore oil workers of the Company who participated in this study.

\section{References}

1) Schnall PL and Landsbergis PA: Job strain and cardiovascular disease. Ann Rev Public Health 15, 381411 (1994)

2) Israel BA, Baker EA, Goldenhar LM and Heaney CA: Occupational stress, safety, and health: conceptual framework and principles foe effective prevention interventions. JOHP 1, 261-286 (1996)

3) Siegrist J and Rodel A: Work stress and health risk behavior. Scand J Work Environ Health 32, 473-481 (2006)

4) Westman M, Eden D and Shirom A: Job stress, cigarette smoking and cessation: the conditioning effects of peer support. Soc Sci Med 20, 637-644 (1985)
5) Green KL and Johnson JV: The effects of psychosocial work organization on patterns of cigarette smoking among male chemical plant employees. Am J Public Health 80, 1368-1371 (1990)

6) Johansson G, Johnson JV and Hall EM: Smoking and sedentary behavior as related to work organization. Soc Sci Med 32, 837-846 (1991)

7) Hellerstedt WL and Jeffery RW: The association of job strain and health behaviors in men and women. Int J Epidemiol 26, 575-583 (1997)

8) Brisson C, Larocque B, Moisan J, Vézina M and Dagenais GR: Psychosocial factors at work, smoking, sedentary behavior, and body mass index: a prevalence study among 6995 white collar workers. JOEM 42, 40-46 (2000)

9) Greenlund KJ, Liu K, Knox S, McCreath H, Dyer AR and Gardin J: Psychosocial work characteristics and cardiovascular disease risk factors in young adults: the cardia study. Soc Sci Med 41, 717-723 (1995)

10) Lindquist TL, Beilin LJ and Knuiman MW: Influence of lifestyle, coping, and job stress on blood pressure in men and women. Hypertension 29, 1-7 (1997)

11) Roxburgh S: Gender differences in the effect of job stressors on alcohol consumption. Add Behav 23, 101107 (1998)

12) Russell M, Cooper ML, Frone MR and Peirce RS: A longitudinal study of stress, alcohol, and blood pressure in community-based samples of blacks and non-blacks. Alcohol Res Health 23, 299-306 (1999)

13) House JS, Landis KR and Umberson D: Social relationships and health. Science 241, 540-545 (1988)

14) Allen J, Markovitz J, Jacobs DR and Knox SS: Social support and health behavior in hostility black and white men and women in CARDIA. Psychosom Med 63, 609-618 (2001)

15) Milligan RAK, Burke V, Richards J, Dunbar D, Spencer M, Balde E and Gracey MP: Health-related behaviors and psycho-social characteristics of 18 year-old Australians. Soc Sci Med 45, 1549-1562 (1997)

16) Gu D, Xin X, Gao J, Zhu Y, Wang H, Zheng R, Duan $\mathrm{X}$, Liu Z, Wang N, Wu X and Chen S: Hostility behavior as risk factor of coronary heart disease. Chin J Epidemiol 21, 441-444 (2000)

17) Sutherland VJ and Flin RH: Stress at sea: a review of working conditions in the offshore oil and fishing industries. Work Stress 3, 269-285 (1989)

18) Sutherland VJ and Cooper CL: Stress in the offshore oil and gas exploration and production industries: an organizational approach to stress control. Stress Medicine 12, 61-78 (1996)

19) Parkes KR: Psychosocial aspects of stress, health and safety on North Sea installations. Scand J Work Environ Health 24, 321-333 (1998)

20) Wagenaar WA, Groeneweg J and Hudson PTW: Promoting safety in the oil industry. Ergonomics 37, 1999-2013 (1994)

21) Mearns K, Flin R, Gordon R and Fleming M: Human and organizational factors in offshore safety. Work Stress 15, 144-160 (2001)

22) Cooper CL and Sutherland VJ: Job stress, mental 
health, and accidents among offshore workers in the oil and gas extraction industries. JOM 29, 119-125 (1987)

23) Cooper CL, Sloan SJ, Williams S. Occupational Stress Indicator Management Guide. Oxford: NFER-Nelson Publishing Company Limited, 1988: 56-64.

24) Sutherland VJ and Cooper CL: Stress in the offshore oil and gas exploration and production industries: an organizational approach to stress control. Stress Medicine 12, 61-78 (1996)

25) Chen WQ, Wong TW and Yu TS: Reliability and validity of the occupational stress scale for Chinese offshore oil installation workers. Stress Health 17, 175183 (2001)

26) Chen WQ, Wong TW, Yu TS, Lin YZ and Cooper CL: Determinants of perceived occupational stress among Chinese offshore oil workers. Work Stress 17, $287-$ 305 (2003)
27) Pomerleau J, Pederson LL, Østbye T, Speechley M and Speechley KN: Health behaviours and socio-economic status in Ontario, Canada. Euro J Epidemiol 13, 613622 (1997)

28) Borrell C, Dominguez-Berjón F, Pasarin MI, Ferrando $\mathrm{J}$, Rohlfs I and Nebot M: Social inequalities in health related behaviours in Barcelona. J Epidemiol Community Health 54, 24-30 (2000)

29) Laaksonen M, Prättälä R and Lahema E: Sociodemographic determinants of multiple unhealthy behaviours. Scand J Public Health 31, 37-43 (2003)

30) Jane O. Health Psychology. Philadelphia: Open University Press, 90-124.

31) Sayette MA: Does drinking reduced stress? Alcohol Res Health 23, 250-255 (1999)

32) Frone MR: Work stress and alcohol use. Alcohol Res Health 23, 284-291 (1999)

\section{Appendix}

Classification and definition of variables

\begin{tabular}{|c|c|}
\hline Variables & Definition or value \\
\hline Age & Year \\
\hline Education level & $\begin{array}{l}\text { Primary school, secondary school, high/technical secondary school, junior } \\
\text { college, and university }\end{array}$ \\
\hline Marital status & Unmarried, married \\
\hline Duration of offshore work & Year \\
\hline Job titles & $\begin{array}{l}\text { Drilling, attending, deck, electricians, mechanics, service, Manager, } \\
\text { material, power, derrick, turbine, and others }\end{array}$ \\
\hline Occupational stress & Factor score \\
\hline Instrumental support from supervisor & $1=$ Lack of support (never, a few, sometimes), $0=$ Strong (often) \\
\hline Instrumental support from colleague & $1=$ Lack of support (never, a few, sometimes), $0=$ Strong (often) \\
\hline Instrumental support from wife/families & $1=$ Lack of support (never, a few, sometimes), $0=$ Strong (often) \\
\hline Instrumental support from friend & $1=$ Lack of support (never, a few, sometimes), $0=$ Strong (often) \\
\hline Emotional support from supervisor & $1=$ Lack of support (never, a few, sometimes), $0=$ Strong (often) \\
\hline Emotional support from colleague & $1=$ Lack of support (never, a few, sometimes), $0=$ Strong (often) \\
\hline Emotional support from Wife/families & $1=$ Lack of support (never, a few, sometimes), $0=$ Strong (often) \\
\hline Emotional support from Friend & $1=$ Lack of support (never, a few, sometimes), $0=$ Strong (often) \\
\hline Do you smoke? & $1=$ Current smoking, $0=$ Never or ex-smoking, \\
\hline Do you drink? & $1=$ Current drinking, $0=$ Never or ex-drinking, \\
\hline How often do you take physical exercise aft & $1=$ Physical inactivity (Never or occasionally), $0=\mathrm{Pl}$ \\
\hline
\end{tabular}

